\title{
Reducing the Entrainment of Gangue Fines in Low Grade Microcrystalline Graphite Ore Flotation Using Multi-Stage Grinding-Flotation Process
}

\author{
Xiaoqing Weng ${ }^{1}$, Hongqiang $\mathrm{Li}^{1}{ }^{1 *}$, Shaoxian Song ${ }^{2}$ and Yanyan Liu ${ }^{2}$ \\ 1 School of Resources and Civil Engineering, Wuhan Institute of Technology, Wuhan 430205, China; \\ xaoqingw@163.com \\ 2 School of Resources and Environmental Engineering, Wuhan University of Technology, Wuhan 430070, \\ China; shaoxian@uaslp.mx (S.S.); wulengheiyin@whut.edu.cn (Y.L.) \\ * Correspondence: 1hq-18@163.com
}

Academic Editor: Massimiliano Zanin

Received: 14 October 2016; Accepted: 6 March 2017; Published: 14 March 2017

\begin{abstract}
A suitable grinding fineness and flow-sheet could potentially reduce the mechanical entrainment of gangue minerals in the flotation process of microcrystalline graphite. In this study, the suitable grinding fineness of a commercial graphite ore was estimated by mineralogy analysis and laboratory grind-flotation tests. The target grind size of this ore should be $92 \%$ passing $74 \mu \mathrm{m}$ based on the mineralogical evaluation and the flotation performance. A comparison of a single-stage and a three-stage grinding circuit was conducted. Experimental results demonstrated that the three-stage grinding circuit could effectively improve the separation effect, which was attributed to the reduction of slimes. In the end, a more desirable beneficiation result was obtained with the application of three-stage grinding-flotation process by minimizing gangue entrainment.
\end{abstract}

Keywords: froth entrainment; multi-stage grinding; multi-stage cleaning; microcrystalline graphite

\section{Introduction}

Natural graphite is found in three commercial varieties: crystalline flake, microcrystalline, and crystalline vein (or lump) [1]. Graphite formed in contact metamorphism of coaly materials as a result of igneous intrusion is referred to as microcrystal graphite (or earthy graphite) [2]. The fixed carbon content on the air dried basis $\left(\mathrm{FC}_{\mathrm{ad}}\right)$ of some European microcrystalline graphite deposits is about $55 \%$ [3], while the $\mathrm{FC}_{\mathrm{ad}}$ of parts of deposits in China is $50 \%-70 \%$. In order to expand its application and get a higher price, it should be upgraded above $80 \%\left(\mathrm{FC}_{\mathrm{ad}}\right)$, or even $90 \%\left(\mathrm{FC}_{\mathrm{ad}}\right)$. For commercial microcrystalline graphite ore with an $\mathrm{FC}_{\mathrm{ad}}$ of $60 \%-70 \%$ can only be upgraded to $80 \%-84 \%\left(\mathrm{FC}_{\mathrm{ad}}\right.$ ) by flotation for its poor beneficiability [4-6].

Graphite is naturally floatable due to its inherent hydrophobic property. Despite the natural floatability, the separation of gangue is normally improved by the addition of a small amount of kerosene as collector and sodium silicate as gangue depressant, and floated with pine oil or methyl isobutyl carbinol (MIBC) as the frother [7]. Besides of quartz/feldspar, graphite is usually associated with layered minerals such as biotite, sericite and kaolinite [8]. Due to the natural interleaving of mica with the flake graphite, it is not possible to produce grades of over $95 \%$ by flotation. The entrainment of sericite also leads to a poor flotation selectivity of the microcrystalline graphite ore [9,10]. Depressants such as starch and carboxylethyl cellulose have been reported to depress clay minerals thereby increase the grade of concentrate [11]. An investigation of reverse flotation separation of sericite from graphite was also conducted using a surfactant: formaldehyde condensate of methyl naphthalene sulfonic sodium salt (MF) [12]. Not only in the graphite flotation, entrainment of gangue also obviously affected 
the grade of concentrate in coal, $\mathrm{Au} / \mathrm{Cu}$ sulphide ore [13], ultrafine sphalerite flotation [14], and the flotation of base metal ores [15].

Many research projects have been carried out to reduce the entrainment of gangues. Some researchers tried to reduce water recovery (thus entrainment) by increasing the flotation rate of hydrophobic particles [16]. In order to encourage the drainage of gangues through the froth zone, technical solutions such as water spray to the froth layer [17], vibration of the froth zone, and the use of a centrifugal force field flotation cell have been tested [13]. Mulleneers modified mechanical flotation cells by adding a counter current sedimentation zone to prevent the entrainment [18]. Cao and Liu proposed that the entrainment of fine and ultrafine hydrophilic particles can be reduced by enlarging their particle size using either inorganic depressants or high molecular weight polymers [19]. Apart from the methods mentioned above, optimizing the grinding fineness and flow-sheet may be an effective way to reduce the entrainment of gangue.

This study aims at the reduction of gangue entrainment and the improvement of the separation selectivity in purification of microcrystalline graphite ore. Mineralogy and laboratory grind-flotation tests were employed to determine a reasonable fineness of grind and the number of grinding stages; the mechanism of how multi-stage grinding facilitates the improvement of flotation selectivity was also investigated using the size distribution analysis. In the end, the optimized three-stage grinding-flotation flow-sheet was applied to the purification of the low grade microcrystalline graphite ore.

\section{Material and Methods}

\subsection{Test Samples and Reagents}

A representative sample $(200 \mathrm{~kg}$ ) of ore was obtained from the Hematoxyl in Board Temple microcrystalline graphite deposit located in Inner Mongolia Autonomous Region, China. The ore was crushed by a double toggle jaw crusher $(\mathrm{PE} 400 \times 250)$ and a roll crushing mill to $<2 \mathrm{~mm}$. Some crushed samples were obtained for mineralogical analysis and chemical composition analysis, the balance was used for flotation tests.

Industrial grade kerosene and emulsifier (OP-10) purchased from Kermel Chemical Reagent Co. (Tianjin, China) were used in these experiments. The collector emulsified kerosene was prepared with a concentration of $50 \mathrm{wt} \%$ by a high-speed blender, namely the kerosene was mixed with water and emulsifier OP-10 in a ratio of 50:100:1. MIBC and sodium silicate depressant were obtained from Charles\&Tennant Company (Toronto, ON, Canada) and Jiandong Company (Yixin, China), respectively.

\subsection{Methods}

\subsubsection{Proximate Analysis}

The proximate analysis of microcrystalline graphite samples was carried out by a Will Sun Automatic Proximate Analyzer in Anhui University of Science \& Technology, Huainan, China.

\subsubsection{X-Ray Diffraction Analysis}

Crystalline phase of raw ore were determined by X-ray diffraction (Bruker, Braun, Germany). X-ray diffraction analysis was conducted by Philips $\mathrm{X}^{\prime}$ Pert Pro Alpha 1 with $\mathrm{Cu} \mathrm{K} \alpha$ radiation $(\mathrm{k}=1.5406 \AA)$, at a tube current of $40 \mathrm{~mA}$ and a voltage of $35 \mathrm{kV}$. Data were collected over $2 \theta$ values from $3^{\circ}$ to $70^{\circ}$ at a scanning speed of $1^{\circ} / \mathrm{min}$.

\subsubsection{Mineralogical Characteristics Analysis}

Mineralogical characteristics of raw ore were analyzed using a Leica Axio imager A2 pol (Leica, Wetzlar, Germany). Fourteen pieces of primary crushed ore were chosen as the samples 
for the optical mineralogy study. Sample pellets were cast into epoxy and impregnated, then cut into half and polished to give a good, reflecting cross section to study with the microscope.

In order to determine whether the graphite aggregates were liberated from gangue minerals or not at the grinding fineness of $92 \%$ passing $74 \mu \mathrm{m}$, mineralogical characteristics of a multiple cleaning concentrate were analyzed. The ground sample $(92 \%$ passing $74 \mu \mathrm{m})$ was subjected to one stage of rougher flotation followed by eight stages of cleaning to reject the entrained gangue minerals as much as possible; then, this multiple cleaning concentrate was observed by optical microscopy and scanning electron microscope (SEM, JEOL, Tokyo, Japan). The samples for SEM observation were prepared in the same method as sample pellets. The samples for optical microscopy observation were prepared as follows: the concentrate was diluted to a ratio of 1:10 to ensure an adequate dispersion of the particles for microscopy; the diluted sample of $0.1 \mathrm{~mL}$ was spread on the microscope slide, which was then dried in an oven before being observed.

\subsubsection{Grinding-Flotation Tests}

To investigate the ultimate grinding fineness of this ore, five grinding fineness including

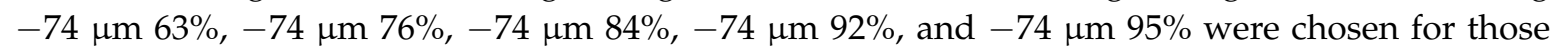
tests. Wet grinding of microcrystalline graphite was conducted in a laboratory steel ball mill $(\mathrm{XMQ} 240 \times 90)$, the solid mass concentration of grinding was fixed at $50 \mathrm{wt} \%$. Bench scale laboratory flotation tests were carried out in a XFDII mechanically agitated flotation machine. First, the ground sample was conditioned for $3 \mathrm{~min}$; next, the depressant sodium silicate, collector kerosene and frother MIBC were added staged to pulp and conditioned; and then, the froth concentrate was scraped out at a rate of once every $5 \mathrm{~s}$ for $10 \mathrm{~min}$, and the mineral particles left in pulp was collected as tailing; finally, flotation products were analyzed for $\mathrm{FC}_{\mathrm{ad}}$. The operating and reagent conditions are presented in Table 1.

Table 1. Operating and reagent conditions of grinding-flotation tests.

\begin{tabular}{|c|c|c|c|c|c|c|c|}
\hline \multirow{2}{*}{$\begin{array}{c}\text { Cell } \\
\text { Volume (L) }\end{array}$} & \multirow{2}{*}{$\begin{array}{l}\text { Air Flow-Rate } \\
\text { (L/min) }\end{array}$} & \multirow{2}{*}{$\begin{array}{c}\text { Impeller } \\
\text { Speed (rpm) }\end{array}$} & \multicolumn{3}{|c|}{ Reagent Dosage (g/t) } & \multirow{2}{*}{$\begin{array}{c}\text { Solids } \\
\text { Weight (g) }\end{array}$} & \multirow[b]{2}{*}{$\mathrm{pH}$} \\
\hline & & & $\begin{array}{l}\text { Sodium } \\
\text { Silicate }\end{array}$ & Kerosene & MIBC & & \\
\hline 1.5 & 4 & 2045 & 1500 & 2000 & 300 & 300 & $8-9$ \\
\hline
\end{tabular}

Separation efficiency (EI) is a quantitative means to specify the optimal grind size. It was calculated as the following equation:

$$
\begin{gathered}
\% C R=\frac{\operatorname{Mc}(100-A c)}{\operatorname{Mf}(100-A f)} \times 100 \\
\% A R=1-\frac{M c A c}{M f A f} \times 100 \\
E I=C R+A R-100
\end{gathered}
$$

where $\mathrm{CR}$ is the combustible recovery; $\mathrm{AR}$ is the ash rejection; EI is the efficiency index; Ac is the ash content in concentrate, \%; Af is the ash content in feed, \%; Mc is the mass of concentrate, g; and Mf is the mass of feed, $g$.

A comparison of a single-stage grinding circuit and a three-stage grinding circuit was conducted. The flow-sheet and reagent conditions are shown in Figure 1. The grinding fineness is listed in Table 2. For the single-stage grinding circuit, the grind size of grinding I was $92 \%$ passing 74 microns, while, for the three-stage grinding circuit, the grind size of grinding I, grinding II and grinding III were $40 \%$, $83 \%$ and $90 \%$ passing 74 microns. 
Table 2. The grinding fineness in grinding stage comparison $(-74 \mu \mathrm{m} / \%)$.

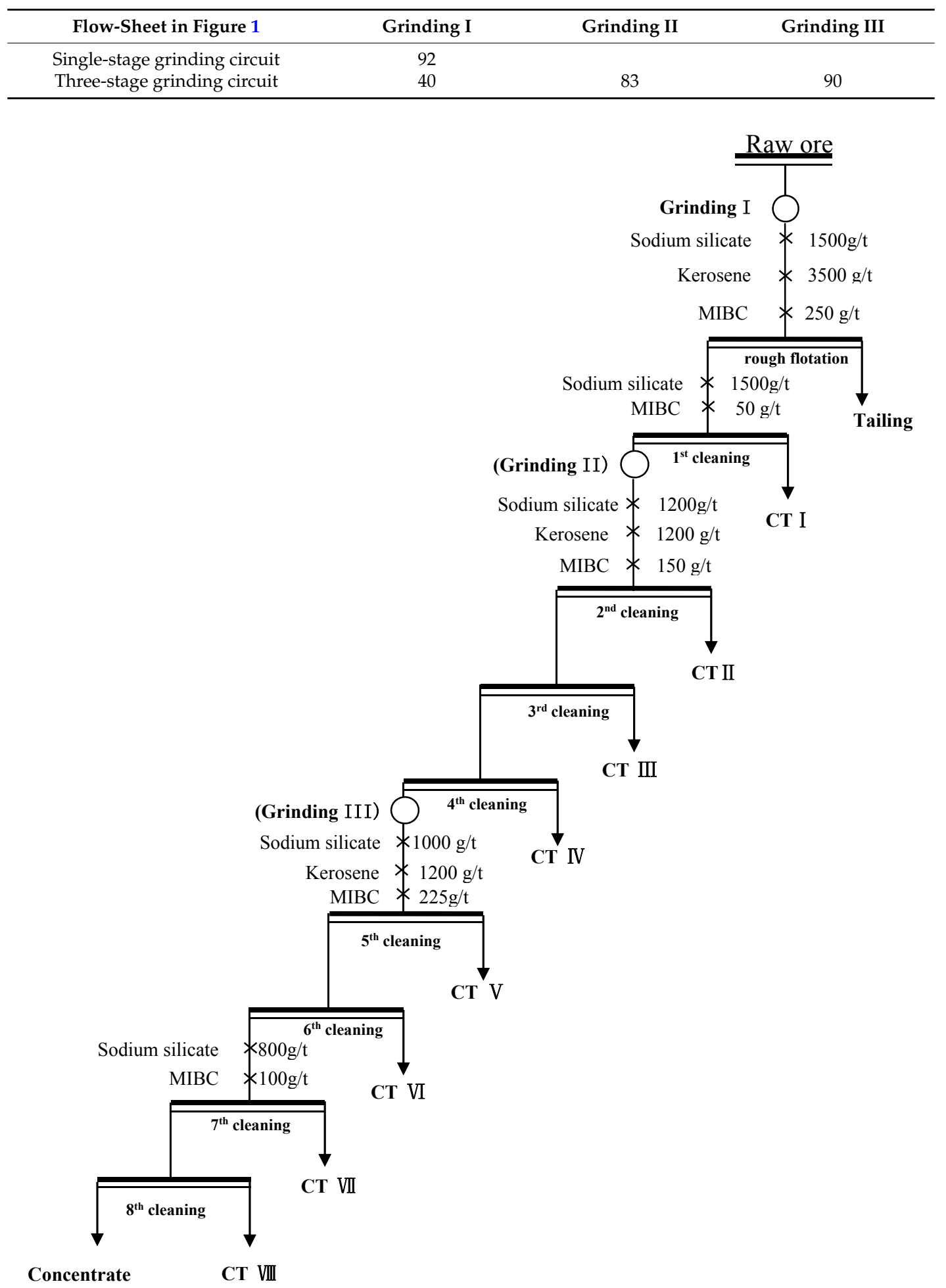

Figure 1. Flowsheet and reagent conditions for comparison of single-stage grinding circuit and three-stage grinding circuit.

In the end, the optimized three-stage grinding-flotation flow-sheet was applied to the purification of the low grade microcrystalline graphite ore. The details of the optimal three-stage grinding-flotation process are shown in Figure 2. 


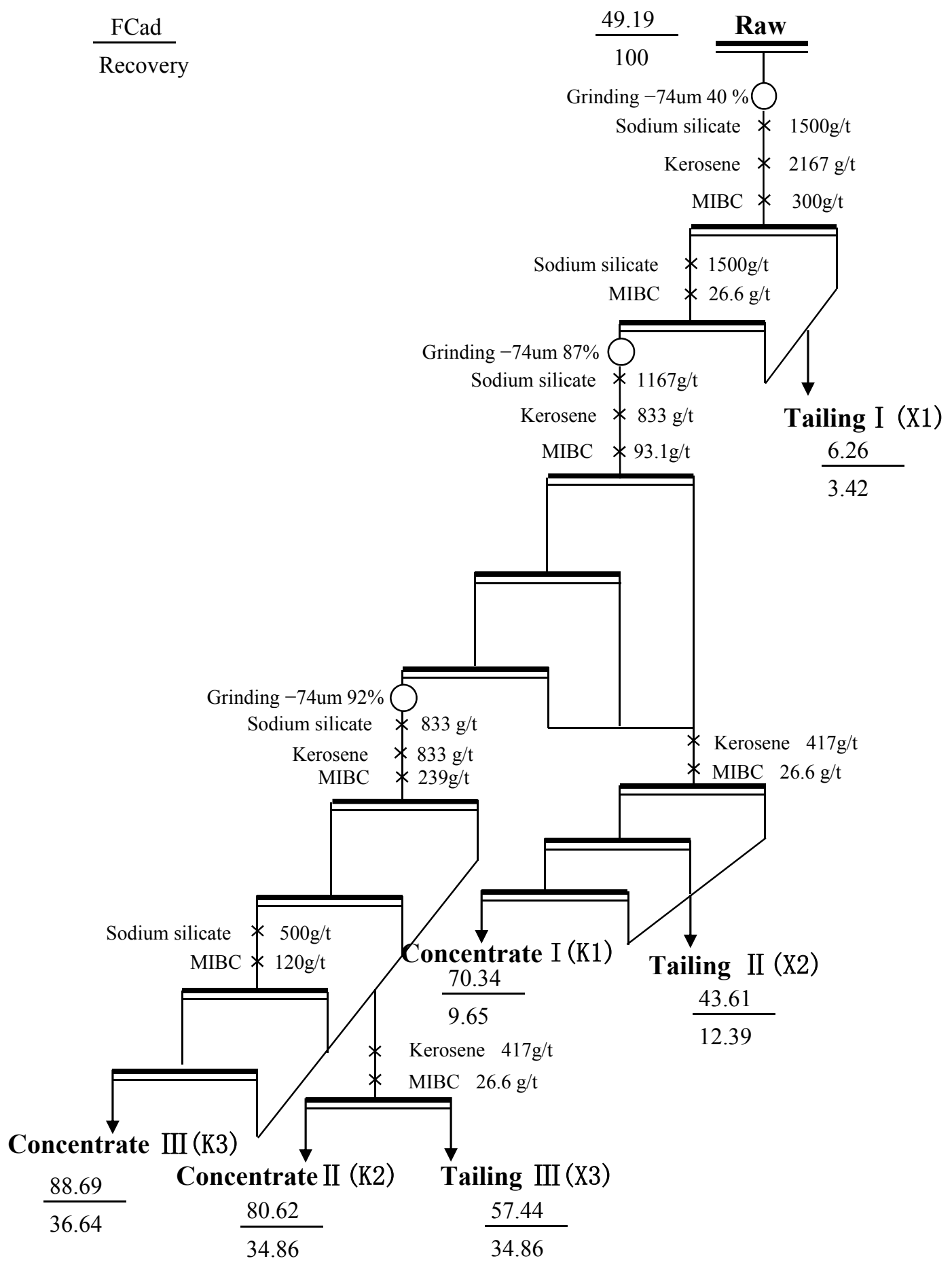

Figure 2. The optimal flow-sheet and reagent conditions of three-stage grinding-flotation process.

\section{Results and Discussion}

\subsection{Mineralogical Characteristics}

The proximate analysis results of the raw ore are presented in Table 3. The ash on air dried basis $\left(\mathrm{A}_{\mathrm{ad}}\right)$ of this sample was $43.45 \%$, which revealed that it was a high ash content sample; the FC $\mathrm{Cd}_{\mathrm{ad}}$ $49.26 \%$, indicating that it belonged to a low-grade ore. 
Table 3. Proximate analysis results of microcrystal graphite raw ore/\%.

\begin{tabular}{cccccc}
\hline Composition & $\mathbf{M}_{\mathbf{a d}}$ & $\mathbf{A}_{\mathbf{a d}}$ & $\mathbf{V}_{\mathbf{a d}}$ & $\mathbf{F C}_{\mathbf{a d}}$ & Sum \\
\hline Content & 3.44 & 43.45 & 3.85 & 49.26 & 100.00 \\
\hline
\end{tabular}

Mad: The moisture of air dried basis; $\mathrm{A}_{\mathrm{ad}}$ : The ash of air dried basis; $\mathrm{V}_{\mathrm{ad}}$ : The volatile matter of air dried basis; $\mathrm{FC}_{\mathrm{ad}}$ : The fixed carbon of air dried basis.

Phase composition of the raw ore was investigated by powder X-ray diffraction and Rietveld quantitative phase analysis. Figure 3 displays the XRD pattern of the raw ore. The content of those minerals is given in Table 4 . The content of the clay minerals reached up to $18 \%$, with the clay minerals including sericite and kaolinite with a small grain size of often less than five microns, which suffers from sliming [20]. It was expected that clay minerals were easily entrained into the froth layers and caused high gangue entrainment in the froth flotation as a result of the fine size [10].

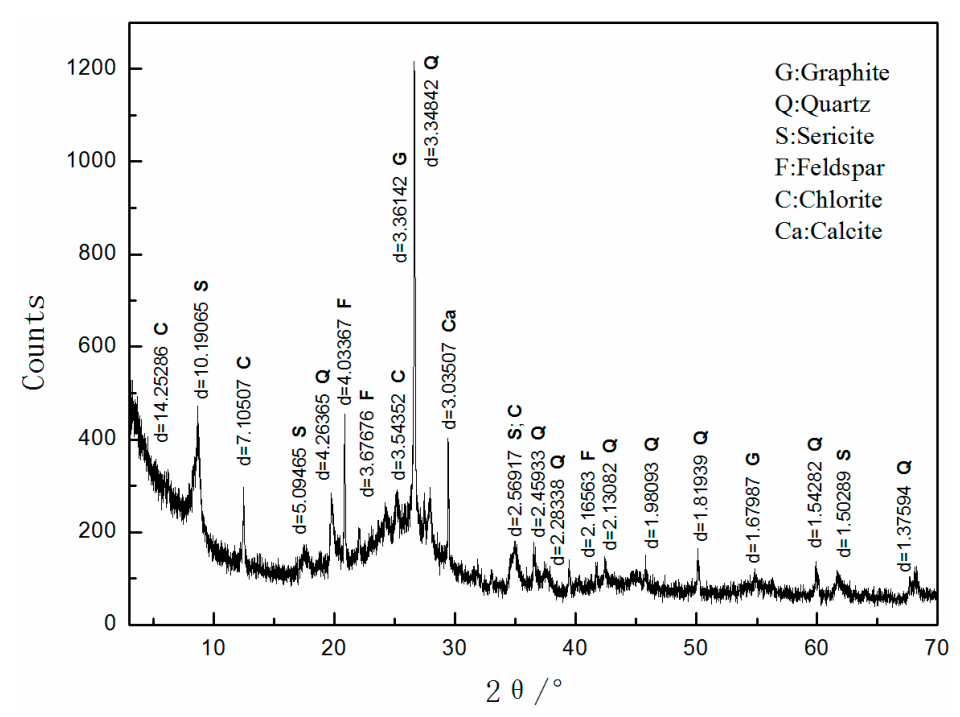

Figure 3. XRD pattern of raw ore ( $\mathrm{FC}_{\mathrm{ad}}$ was $\left.49.26 \%\right)$.

Table 4. Mineral composition of the ore sample/wt \%.

\begin{tabular}{ccccccc}
\hline Minerals & Graphite & Quartz & Feldspar & Sericite & Kaolinite & Others \\
\hline Content & 55 & 20 & 5 & 14 & 4 & 2 \\
\hline
\end{tabular}

The mineralogical knowledge, particularly the ore texture, is required if efficient processing is to be carried out. The texture refers to the grain size, dissemination, association and shape of minerals within the ore. Optical microscopy research can provide ore texture information as shown in Figure 4. Grind size can be estimated with the aggregate size of graphite. The aggregate size of graphite was heterogeneous, which varied greatly from $150 \mu \mathrm{m}$ to $1 \mu \mathrm{m}$, usually ranging from $60 \mu \mathrm{m}$ to $20 \mu \mathrm{m}$ (Figure $4 a, b)$. In Figure $4 b$, irregular granular microcrystalline graphite $(M)$ was disseminated in the gangue $(\mathrm{G})$, and the association of minerals was very complicated. 


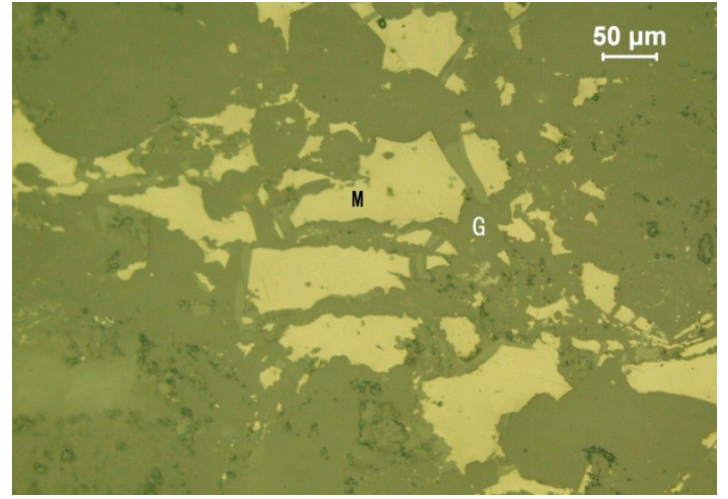

(a)

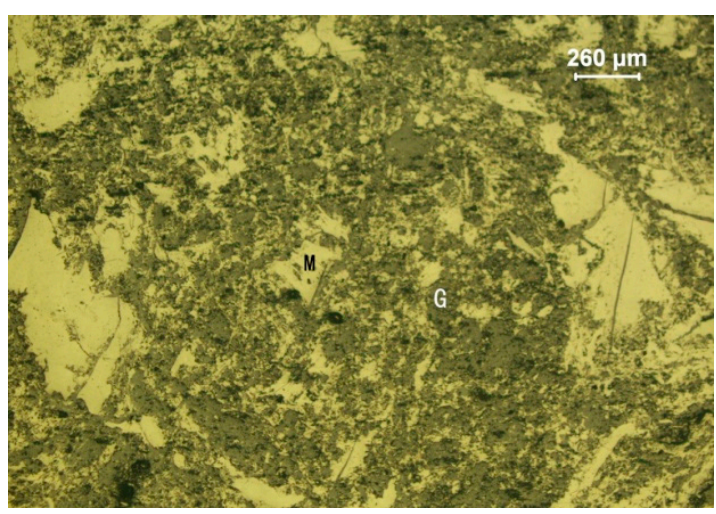

(b)

Figure 4. Optical mineralogy of raw ore. (a) Irregular granular microcrystal graphite (M) is disseminated in the gangue (G). Reflected light. (b) Fine-grained microcrystal graphite (M) is disseminated in the gangue $(\mathrm{G})$ (gray and black); gangue is mainly sericite. Reflected light.

\subsection{Determination of the Ultimate Grinding Fineness}

As the entrainment of gangue minerals was closely dependent on particle size, the ore should not be ground any finer than its liberation fineness. A single stage of flotation was performed on the samples ground to various degrees. The flotation tests were repeated three times. The average results and error bars are given in Figure 5.
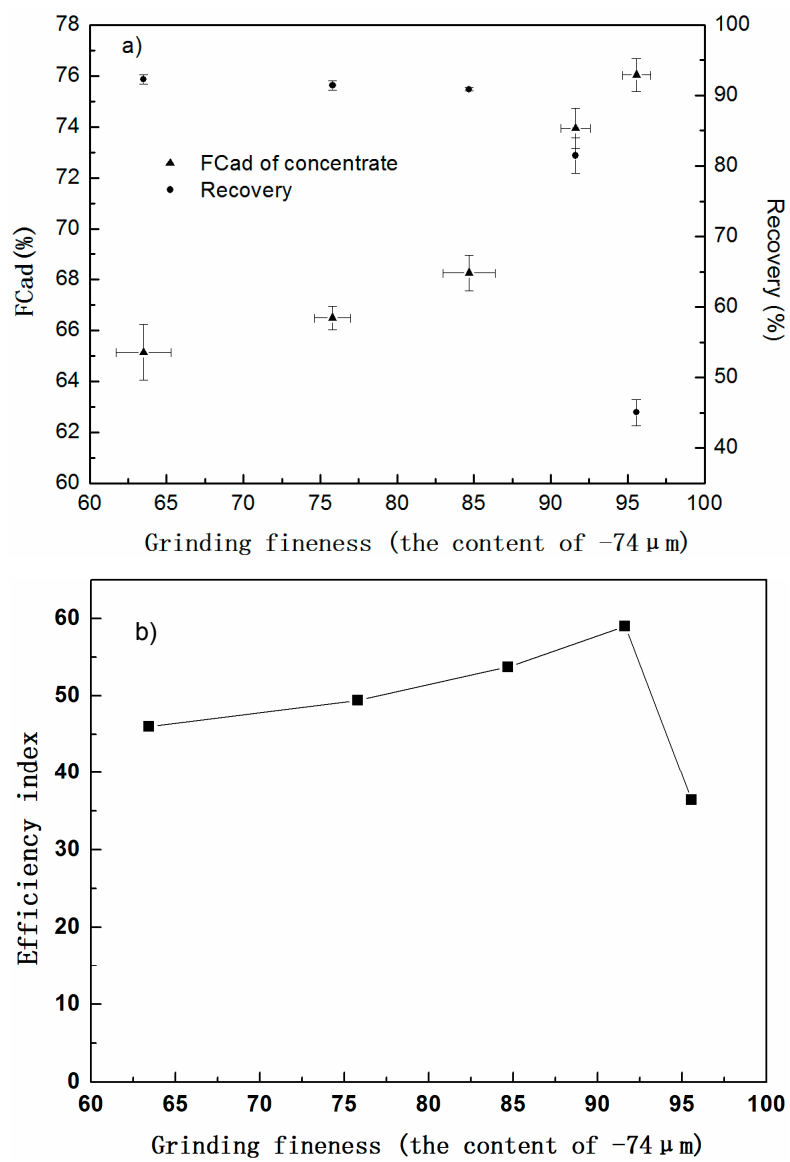

Figure 5. The effect of grinding fineness on: (a) $\mathrm{FC}_{\mathrm{ad}}$ of concentrate and recovery; (b) separation efficiency. 
The flotation selectivity was efficiently improved with the grind size decreasing from $-74 \mu \mathrm{m}$

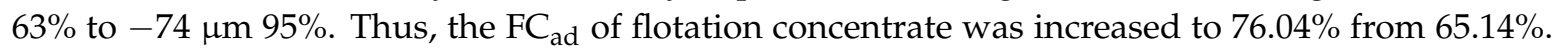
The recovery of graphite was sharply reduced from $92.28 \%$ to $45.06 \%$ likely due to insufficient collectors. Because the decrease of the grind size led to a significant increase of the surface area, more collector was required to make the surface of fine graphite particles hydrophobic.

The effect of grinding fineness on separation efficiency are presented on Figure 5b. Obviously, the efficiency index reached a peak at the grind size of $92 \%$ passing $74 \mu \mathrm{m}$. Thus, the suitable grind size was around $92 \%$ passing $74 \mu \mathrm{m}$ which gives a reasonable concentrate $\mathrm{FC}_{\mathrm{ad}}$ and recovery in rougher flotation.

If the graphite aggregates were liberated from gangue minerals at the suitable grinding fineness of $92 \%$ passing $74 \mu \mathrm{m}$, a multiple cleaning concentrate at the grinding fineness of $-74 \mu \mathrm{m} 92 \%$ was observed by optical microscopy and scanning electron microscope (SEM). The FC $\mathrm{Fd}_{\mathrm{ad}}$ of this flotation concentrate was $88.5 \%$, suggesting that a relative high grade product could be obtained at the grind size of $92 \%$ passing $74 \mu \mathrm{m}$. The optical microscope image and secondary electron image of flotation concentrate are shown in Figure 6. The optical microscope image (Figure 6a) showed that the liberated gangue particles (the white spots) left in the concentrate were likely recovered by entrainment. The secondary electron images by SEM of the flotation concentrate (Figure 6b) clearly revealed that the vast majority of graphite aggregates $(G)$ with high purity, apart from the liberated gangue particles (the white spots). It was hard to find gangue mineral disseminated even in the graphite aggregates at the size of approximate $50 \mu \mathrm{m}$.

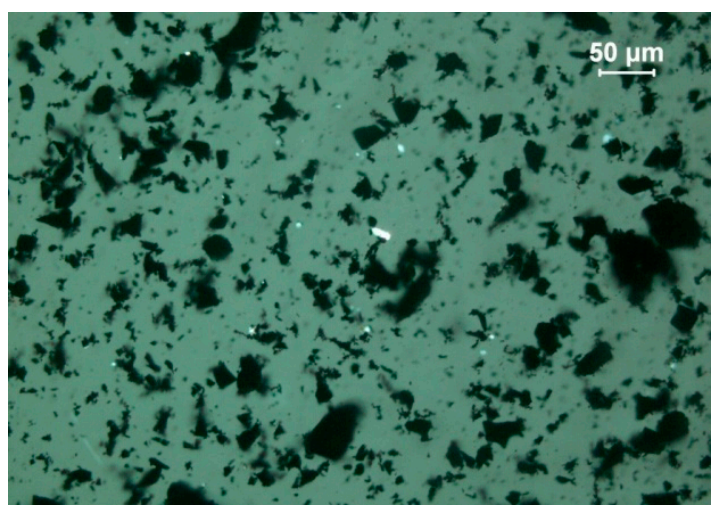

(a)

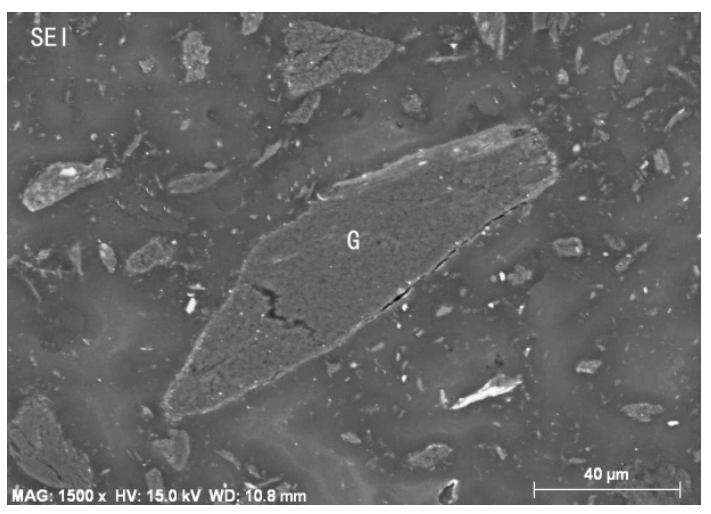

(b)

Figure 6. The images of flotation concentrate. (a) The white spots are gangue particles; the dark spots are graphite particles, optical microscope image. (b) Microfine vermicular graphite $(G)$ gets together and forms into lenticular aggregates. Secondary electron image by SEM.

\subsection{Comparison of Single-Stage Grinding Circuit and Three-Stage Grinding Circuit}

The ultimate grinding fineness of the sample was around $92 \%$ passing $74 \mu \mathrm{m}$. Two strategies of grinding were proposed for consideration: a single-stage of grinding and a multi-stage grinding flow-sheet. Generally, a single-stage grinding flow-sheet is more convenient for process management and is typically employed in the processing of a homogeneous grained ore; a multi-stage grinding flow-sheet incurs lower electricity consumption because parts of gangue minerals discharged at a coarse particle size.

The flow-sheet and reagent scheme are given in Figure 1. The grinding fineness is shown in Table 2. The final grinding fineness of both the single-stage grinding flow circuit and the three-stages grinding circuit was approximately $91 \%-74 \mu \mathrm{m}$. For each circuit, the flotation tests were repeated three times. The average results and error bars are given in Figure 7.

As shown in Figure 7, the recovery and separation selectivity were remarkably improved when the three-stage grinding circuit was employed. In the single-stage grinding circuit, the recovery 
and $\mathrm{FC}_{\mathrm{ad}}$ of the flotation concentrate were $27.77 \%$ and $86.52 \%\left(\mathrm{FC}_{\mathrm{ad}}\right)$. For the three-stage grinding circuit, the $\mathrm{FC}_{\mathrm{ad}}$ of concentrate was increased by $1.93 \%$ to $88.45 \%\left(\mathrm{FC}_{\mathrm{ad}}\right)$, meanwhile the recovery was drastically increased by $11.38 \%$ to $39.15 \%$. In addition, the cumulative recovery (concentrate, CTI, CTII, CTIII, CTIV, CTV, CTVI, CTVII and CTVIII) is $4.94 \%$ higher for the grinding circuit with three-stages.
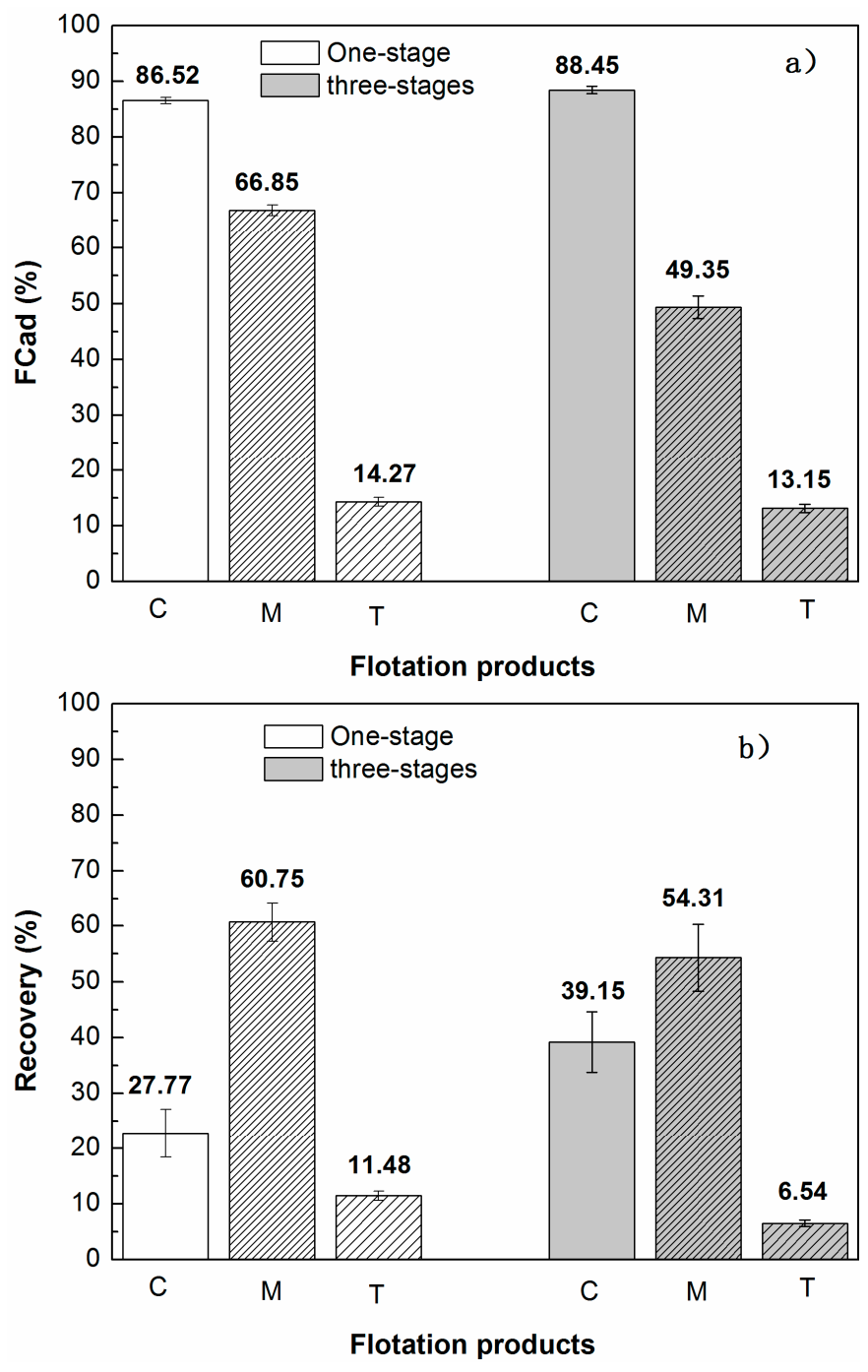

Figure 7. Effect of grinding stage on (a) $\mathrm{FC}_{\mathrm{ad}}$ of products; (b) Recovery of products.

In the three-stage grinding circuit, one possible mechanism which led to the beneficial effects on the separation effect was proposed: reducing the foam entrainment of gangue slimes.

The recovery of gangue minerals by entrainment closely depends on the particle size of both hydrophilic minerals and hydrophobic valuable minerals [21,22]. At the first-stage grinding-flotation circuit, a large part of gangue minerals such as sericite and kaolinite, which suffer from sliming, were discharged into the tailing at a coarse particle size, a typical value for coarse particles is often $+75 \mu \mathrm{m}$ [23]. In the second and third stage of grinding, a small amount of gangue was left and fewer over-ground particles were generated. A comparison of the particle size distribution of the feed in the fifth stage of cleaning was carried out using laser particle size analysis. The results are shown in Figure 8. It is clearly indicated that the content of slimes $(<5 \mu \mathrm{m})$ in the three-stage grinding flotation circuit was obviously lower than the single-stage grinding flotation circuit. Therefore, in the three-stage grinding flotation circuit, the amount of gangue slimes recovered by froth entrainment was significantly reduced from the second cleaning to the eighth cleaning. The flotation selectivity was 
significantly improved as shown in Figure 9. The $\mathrm{F}_{\mathrm{Cad}}$ difference between concentrate and tailings from the second cleaning to the eighth cleaning was remarkably higher, as compared to that of single-stage grinding circuit.

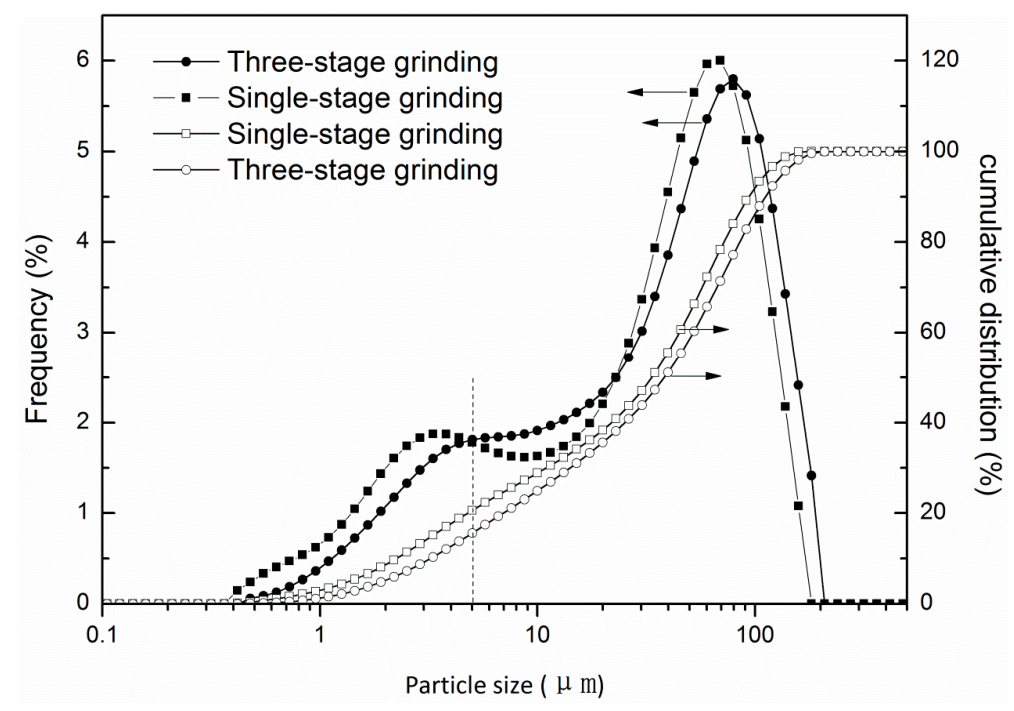

Figure 8. The particle size distribution of feed in the fifth stage of cleaning.

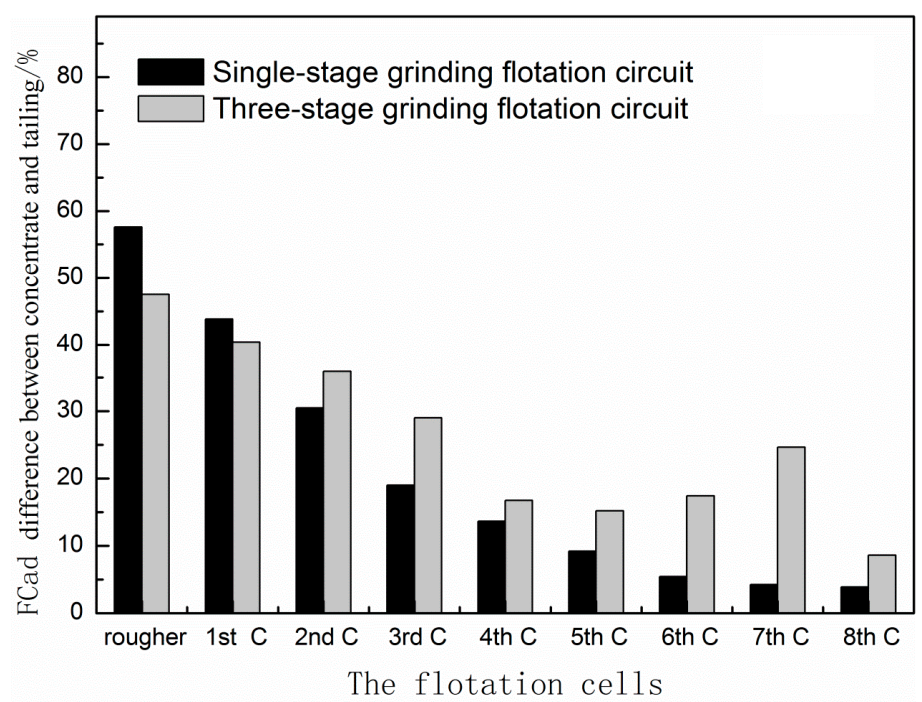

Figure 9. Effect of grinding stage on the flotation selectivity.

The results of these experiments strongly supported that the multi-stage grinding was an effective solution to reducing the foam entrainment of fine gangue minerals.

\subsection{Application of the Multi-Stage Grinding Flotation Process}

The multi-stage grinding flotation process was proposed in the purification of microcrystalline graphite. The optimal three-stage grinding flotation circuit was used in purification of this sample. The details of the optimal three-stage grinding flotation process are shown in Figure 2. The grinding fineness of the first, second and third stage were $-74 \mu \mathrm{m} 40 \%,-74 \mu \mathrm{m} 87 \%$ and $-74 \mu \mathrm{m} 92 \%$, respectively. After the grinding process, multi-stages of cleaning were carried out to remove the liberated gangue particles as much as possible. Entrainment of the gangue increased with the decrease of the particle size, thus three stages of cleaning should be carried out after the third stage of grinding 
to reject the entrainment gangue, while only single stage of cleaning was conducted after the first stage of grinding. A large number of middles were generated after stages of cleaning. To increase the recovery of graphite, recleaning of middles were necessary, the recleaning concentration with low purity are suitable for different markets. The results are given in Table 5.

Three types of concentrate were obtained. The total recovery reached $81.16 \%$. The high grade concentrate (K3) met the standard of WT88 with the fraction recovery of $36.64 \%$, which could be used as the raw material in the production of, for example, anodes, pencils and graphite bearings. The middle grade concentrate (K2) met the standard of W80 with the fraction recovery of $34.86 \%$, which was usually used in the fields of, for example, manufacturing refractory materials, foundry technology and electrode manufacture. The low grade concentrate (K1) with a lower price could also be obtained in the flow-sheet, with a recovery of $9.65 \%$.

Table 5. The flotation results of three-stage grinding-flotation process.

\begin{tabular}{cccccc}
\hline Product & Yield/\% & $\mathbf{F C}_{\mathbf{a d}} / \%$ & Recovery/\% & $\begin{array}{c}\text { Product } \\
\text { Number }\end{array}$ & Application Field \\
\hline K1 & 7.4 & 70.34 & 9.65 & W70 & Foundry, refractory material, \\
dye and electrode.
\end{tabular}

\section{Conclusions}

In this study, a suitable grinding strategy was investigated to reduce the mechanical entrainment of gangue minerals in flotation of microcrystalline graphite ore. The conclusions were drawn as follows:

(1) The results of mineralogical evaluation and grinding flotation tests indicated that a high grade graphite concentrate could be obtained at the fineness of $92 \%$ passing $74 \mu \mathrm{m}$.

(2) Multi-stage grinding-flotation process can effectively reduce the froth entrainment of gangues; the reduction of gangue slimes plays a vital role in the improvement of the separation effect.

(3) The high grade concentrate which meets the standard of WT88 could be obtained with a recovery of $36.64 \%$ using a three-stage grinding flotation process.

Acknowledgments: Support from the National Natural Science Foundation of China (project No. 51504176 and project No. 51474167) is gratefully acknowledged.

Author Contributions: Xiaoqing Weng and Hongqiang Li conceived and designed the experiments; Xiaoqing Weng and Hongqiang Li prepared the samples and performed the experiments; Hongqiang Li and Shaoxian Song analyzed the data. Xiaoqing Weng, Hongqiang Li, Shaoxian Song and Yanyan Liu contributed to the writing and revising of the paper.

Conflicts of Interest: The authors declare no conflict of interest.

\section{References}

1. Crossley, P. Graphite. Ind. Miner. 1999, 386, 31-47.

2. Zheng, Z.; Zhang, J.; Huang, J.Y. Observations of microstructure and reflectivity of coal graphites for two locations in China. Int. J. Coal Geol. 1996, 30, 277-284. [CrossRef]

3. Simandl, G.J.; KenanI, W.M. Microcrystalline Graphite; British Columbia Geological Survey: Vancouver, BC, Canada, 1997; pp. 1-4.

4. Ji, G.C. Continuous flotation experiment of microcrystalline graphite. Non-Met. Mines 1991, 2, $16-18$. 
5. Xia, Y.K.; Ren, Z.M.; Chen, H.X.; Guan, A.F.T. A noval flotation flowsheet of microcrystalline graphite and its industrial application. Non-Met. Mines 1996, 111, 26-28.

6. Dong, F.Z. A study on flotation of a cryptocrystalline graphite ore. Conserv. Util. Miner. Resour. 1997, 1, 15-17.

7. Aslan, N.; Cifci, F.; Yan, D. Optimization of process parameters for producing graphite concentrate using response surface methodology. Sep. Purif. Technol. 2008, 59, 9-16. [CrossRef]

8. Acharya, B.C.; Rao, D.S.; Prakash, S.; Reddy, P.S.R.; Biswal, S.K. Processing of low grade graphite ores of orissa, India. Miner. Eng. 1996, 9, 1165-1169. [CrossRef]

9. Liu, D.; Peng, Y. Reducing the entrainment of clay minerals in flotation using tap and saline water. Powder Technol. 2014, 253, 216-222. [CrossRef]

10. Li, H.; Ou, L.; Feng, Q.; Chang, Z. Recovery mechanisms of sericite in microcrystalline graphite flotation. Physicochem. Probl. Miner. Process. 2015, 51, 386-399.

11. Pugh, R.J. Non-ionic polyethylene oxide frothers in graphite flotation. Miner. Eng. 2000, 13, 151-162. [CrossRef]

12. Qiu, Y.; Yu, Y.; Zhang, L.; Qian, Y.; Ouyang, Z. An Investigation of Reverse Flotation Separation of Sericite from Graphite by Using a Surfactant: MF. Minerals 2016, 6, 57. [CrossRef]

13. Gong, J.P.; Bouajila, Y.; Ourriban, A.; Yeung, M.; Liu, Q. Reducing quartz gangue entrainment in sulphide ore flotation by high molecular weight polyethylene oxide. Int. J. Miner. Process. 2010, 97, 44-51. [CrossRef]

14. Duarte, A.C.P.; Grano, S.R. Mechanism for the recovery of silicate gangue minerals in the flotation of ultrafine sphalerite. Miner. Eng. 2007, 20, 766-775. [CrossRef]

15. Silvester, E. The recovery of sericite in flotation concentrates. Miner. Process. Extr. Metall. 2011, 120, 10-14. [CrossRef]

16. Akdemir, Ü.; Taki, G.; Yildiztekin, A.G. Flotation and entrainment behavior of minerals in talc-calcite separation. Scand. J. Metall. 2005, 34, 241-244. [CrossRef]

17. Kirjavainen, V.M. Review and analysis of factors controlling the mechanical flotation of gangue minerals. Int. J. Miner. Process. 1996, 46, 21-34. [CrossRef]

18. Mulleneers, H.; Koopal, A.L.K.; Bruning, H.; Rulkens, A.W.H. Selective separation of fine particles by a new flotation approach. Sep. Sci. Technol. 2002, 37, 2097-2112. [CrossRef]

19. Cao, M.L.; Liu, Q. Reexamining the functions of zinc sulfate as a selective depressant in differential sulfide flotation-The role of coagulation. J. Colloid Interface Sci. 2006, 301, 523-531. [CrossRef] [PubMed]

20. Bergaya, F.; Lagaly, G. Handbook of Clay Science; Newnes: Melbourne, Australia, 2013.

21. Ata, S.; Ahmed, N.; Jameson, G. The effect of hydrophobicity on the drainage of gangue minerals in flotation froths. Miner. Eng. 2004, 17, 897-901. [CrossRef]

22. Neethling, S.J.; Cilliers, J.J. The entrainment factor in froth flotation: Model for particle size and other operating parameter effects. Int. J. Miner. Process. 2009, 93, 141-148. [CrossRef]

23. Newcombe, B.; Bradshaw, D.; Wightman, A.E. Flash flotation and the plight of the coarse particle. Miner. Eng. 2012, 34, 1-10. [CrossRef]

(C) 2017 by the authors. Licensee MDPI, Basel, Switzerland. This article is an open access article distributed under the terms and conditions of the Creative Commons Attribution (CC BY) license (http://creativecommons.org/licenses/by/4.0/). 